\title{
Assessing Livelihood Vulnerability to Salinity Intrusion and Climate Variability-A Case Study in Coastal Provinces of the Mekong River Delta of Vietnam
}

\author{
Nguyen Duy Can \\ Department of Rural Socio-economics, College of Rural Development, Can Tho University, Can Tho 900000, Vietnam
}

\begin{abstract}
Both ST (Soc Trang) and KG (Kien Giang) are coastal provinces of the Mekong River Delta and are most vulnerable to saline intrusion and climate variability. In 2016, thousands of Hhs (Households) in these coastal provinces were at risk due to severe drought and saline intrusion. This study applied the LVI (Livelihood Vulnerability Index) to estimate saline intrusion vulnerability of those two provinces. Data on socio-demographics, livelihoods, health, social networks, physical, financial and natural resources, natural disasters and climate variability were collected from a survey of $298 \mathrm{Hhs}$. From these data, the LVI of each coastal province was calculated. Results show that the overall LVI of KG province is higher than that of ST province. The analysis revealed that this practical method can be applied in different circumstances of climate change and purposes.
\end{abstract}

Key words: Coastal provinces, Mekong River Delta, LVI, saline intrusion and climate variability.

\section{Introduction}

The Mekong River Delta is amongst the most vulnerable regions in South Vietnam. According to predictions it has been reported that 40 percent of the delta could be submerged if sea levels rise by one meter in decades to come, as levels are currently rising at the rate of $3 \mathrm{~mm}$ per year [1]. CC (Climate Change) is believed to be causing the rise of sea levels, which in turn leads to an increase in salt content of water to land that is used for rice paddies, coconut groves and other crops. The Mekong River Delta is home to more than 17.5 million people and produces around half of the country's agro-products. Under CC with the possibility of sea level rise, and SI (Salinity Intrusion) frequently, the heavily populated coastal provinces are expected to be at greatest risk of sea level rise and saline intrusion [2].

To estimate CC vulnerability, the LVI (Livelihood Vulnerability Index) was developed by using multiple

Corresponding author: Nguyen Duy Can, Ph. D., Associate Professor, research field: livelihoods analysis and climate change. indicators to assess exposure to natural disasters and climate variability, social and economic characteristics of Hhs (Households) that affect their adaptive capacity, and current health, food, and water resource characteristics that determine their sensitivity to $\mathrm{CC}$ impacts [3-5]. The LVI analysis was first applied in Mozambique [6], then in other countries such as Nepal, Ghana, Trinidad and Tobago, and recently in the Mekong River Delta [7-10].

Mekong River Delta has a long coastal line of about $780 \mathrm{~km}$. There is an increasing frequency of SI in the coastal areas that leads thousands of villagers to be vulnerable to SI, especially worst drought and SI in 2016 [11]. SI is associated with sea level rise and climate variability, and SI in this delta will become worse and worse in future [1, 2, 10, 11].

KG (Kien Giang) and ST (Soc Trang) are both coastal provinces and most vulnerable to sea levels rise, SI. However, KG is considered to be affected by the West Sea climate, while ST by the East Sea climate. For instance, worst drought and SI in 2016 caused a big damage on agriculture in $\mathrm{KG}$ and $\mathrm{ST}$ with over 54,000 ha and 9,500 ha of paddy with no 
harvest, respectively [12]. Approximately, a total value of damages due to drought and SI in 2016 was about US \$75 million for KG and \$32 million for ST. Recently, SI caused severe losses in agriculture and erosion along coastal line of KG. Most of the KG and ST population are engaged in agriculture, typically in rice cultivation, rice-shrimp farming with over $20 \%$ earning income below the poverty line. Therefore, there is a major concern that sea levels rise and SI will cause rural poverty as it poses a major threat to people's livelihoods through destructive impacts on infrastructure and the environment as well as disturbance to livelihood activities.

This study aims to improve understanding of people's livelihoods and vulnerability in coastal areas of KG and ST provinces. It is based on an empirical study of livelihood assets and use of LVI to estimate livelihood vulnerability to $\mathrm{CC}$, particularly SI at community or district levels.

\section{Material and Methods}

This study adopted the SLF (Sustainable Livelihood Framework) [4] to guide the assessment of livelihood vulnerability to SI. In the SLF, Vulnerability Context is a major determinant of sustainability of livelihood assets as it directly influences livelihood strategies, institutional process, and livelihood outcomes of the community [3, 5, 7]. Under the context of SLF, the vulnerability level of a community determines the impacts of SI and climate variability on people's livelihood assets and strategies.

\subsection{Constructing LVI}

This study aimed to calculate the level of vulnerability under impacts of worst SI and CC in two coastal provinces of $\mathrm{KG}$ and $\mathrm{ST}$ by employing the LVI developed by Hahn [6] and Can [7]. Indicators, or sub-components, of community vulnerability to $\mathrm{CC}$ and SI impacts are grouped into 10 major components presented in Table 1. These components were classified under 5 different livelihood assets of Hhs in the SLF: Human, Physical, Social, Natural, Financial capitals; comprising of Health, Knowledge and skills, Livelihood strategy, Land, Natural resources, Natural disasters and climate variability, Socio-demographic conditions, Social networks, Housing and production means, and Finance and incomes. Each major component includes several indicators or sub-components developed based on available data collected through Hh surveys on CC and SI impacts in KG and ST provinces.

\subsection{Calculating the LVI}

In this study, the LVI was calculated by employing the methods that Hahn [6] and Can [7] developed and used. In particular, for this purpose the equation used in the Human Development Index to calculate the life expectancy index [5], and in LVI to assess risks through Hahn [6] and Can [7] was applied:

$$
\text { index }_{s p}=\frac{S_{p}-S_{\min }}{S_{\max }-S_{\min }}
$$

where $S_{p}$ is the value of sub-component for province $p$; $S_{\min }$ and $S_{\max }$ are the minimum and maximum values, respectively, from data of that sub-component in both provinces.

After normalizing sub-component values, the value of each major component was calculated by Eq. (2):

$$
M_{p j}=\frac{\sum_{i=1}^{n} i_{n d e x_{s p i}}}{n}
$$

where $M_{p j}$ is value of major component $j$ for province $p$; index $_{s p i}$ represents the value of sub-component $s$ indexed by $i$ of major component $\mathrm{M} j$; and $n$ is the number of sub-components in major component $\mathrm{Mj}$.

These ten major component values were directly used in Eq. (3) or aggregated to five values for livelihood assets [Human capital $(\mathrm{H})$, Natural capital (N), Social capital (S), Physical capital (P) and Financial capital (F)] before being used in Eq. (4) to obtain the weighted average of LVI: 
Table 1 Capitals, major components and sub-components comprising the LVI.

\begin{tabular}{|c|c|c|}
\hline Capitals & Major component & Sub-component/indicator \\
\hline \multirow{10}{*}{ Human } & \multirow{2}{*}{ Health } & Percentage of Hhs with member(s) illness \\
\hline & & Percentage of Hhs with member(s) getting illness due to CC and SI \\
\hline & \multirow{4}{*}{ Knowledge \& skills } & Percentage of unlettered Hh heads \\
\hline & & Percentage of Hh heads that just passed primary school \\
\hline & & Percentage of Hh heads that do not know CC \& SI \\
\hline & & Percentage of Hh heads without any training to cope with CC \& SI \\
\hline & \multirow{4}{*}{ Livelihood strategies } & Average agric. livelihood diversity $[1 /($ No. of agric. activities +1$)]$ \\
\hline & & Hhs dependent on agri. as major source of income \\
\hline & & Hhs with no members doing non-farm activities \\
\hline & & Hhs with no job during SI period \\
\hline \multirow{7}{*}{ Natural } & \multirow{2}{*}{ Land } & Percentage of landless Hhs \\
\hline & & Percentage of Hhs that do not cultivate 2 or 3 crops \\
\hline & \multirow{2}{*}{ Natural resources } & Percentage of Hhs that depend on freshwater \\
\hline & & Percentage of Hhs with water shortage in dry season \\
\hline & \multirow{3}{*}{$\begin{array}{l}\text { Natural disasters and climate } \\
\text { variability }\end{array}$} & Average number of severe SI in the past 10 years \\
\hline & & Percentage of Hhs with land affected by SI \\
\hline & & Ave. Hhs with accident due to $\mathrm{CC}$ in the past 20 years \\
\hline \multirow{6}{*}{ Social } & \multirow{4}{*}{ Socio-demographic conditions } & Dependency ratio \\
\hline & & Percentage of Hh female heads \\
\hline & & Average member in an Hh family \\
\hline & & Percentage of poor Hhs \\
\hline & \multirow{2}{*}{ Social networks } & Percentage of Hhs that do not receive help due to disaster 2016 \\
\hline & & Percentage of Hhs that have not been member of any organizations \\
\hline \multirow{3}{*}{ Physical } & \multirow{3}{*}{ Housing \& production means } & Percentage of Hhs with temporary houses \\
\hline & & Percentage of Hhs with no access to production means \\
\hline & & Percentage of Hhs with no access to salinity prevention dykes \\
\hline \multirow{3}{*}{ Financial } & \multirow{3}{*}{ Finance and incomes } & Percentage of Hhs borrowing money \\
\hline & & Percentage of Hhs with annual net Hhs income lower than US $\$ 1,000 /$ year \\
\hline & & Percentage of Hhs without income due to SI \\
\hline
\end{tabular}

$$
\begin{gathered}
L V I_{p}=\frac{\sum_{j=1}^{10} w_{M j} M_{p j}}{\sum_{j=1}^{10} w_{M j}} \\
L V I_{p}=\frac{w_{H} H_{p}+w_{N} N_{p}+w_{S} S_{p}+w_{p} P_{p}+w_{F} F_{p}}{w_{H}+w_{N}+w_{S}+w_{P}+w_{F}}
\end{gathered}
$$

where $L V I_{p}$ is the LVI of province $p ; w_{M j}$ is weight value of major component $j ; w_{\mathrm{H}}, w_{\mathrm{N}}, w_{\mathrm{S}}, w_{\mathrm{P}}, w_{\mathrm{F}}$ are weight value of asset $\mathrm{H}, \mathrm{N}, \mathrm{S}, \mathrm{P}, \mathrm{F}$, respectively. The LVI is ranged from 0 to 1 with 0 denoting least vulnerable and 1 denoting most vulnerable.

\subsection{Study Area and Hh Surveys}

The study and surveys were carried out in KG and ST provinces, in a coastal area of Vietnamese Mekong Delta (locations in Fig. 1). KG has a total area of 634,852 ha of which 575,697 ha are agricultural land with $200 \mathrm{~km}$ coastal line, meanwhile ST province has a total area of 331,176 ha of which $82.89 \%$ of total land is agricultural land with main rice crops. The population of $\mathrm{KG}$ province is $1,792,600$ inhabitants of which $70.5 \%$ live in rural areas, while in ST it is $1,314,300$ inhabitants of which $69.4 \%$ live in rural. 


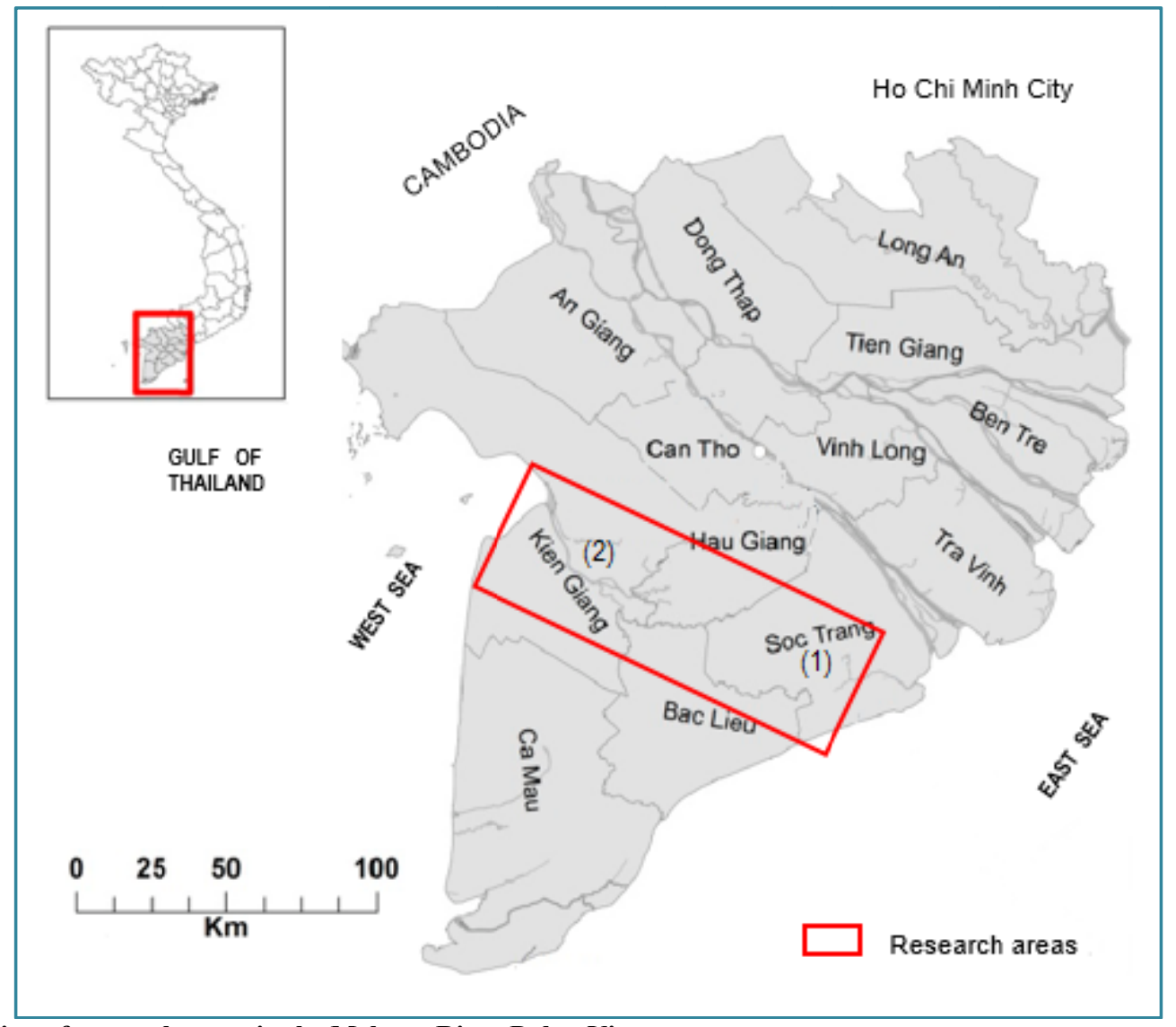

Fig. 1 Location of research areas in the Mekong River Delta, Vietnam.

ST: a coastal province which is affected by East Sea climate; KG: a coastal province which is affected by West Sea climate.

Hhs to survey were selected by simple random sampling, about $150 \mathrm{Hhs}$ for each province. Other criteria that Hhs have lived in the area most vulnerable to $\mathrm{CC}$ and SI were considered. Interviews were conducted by researchers from Can Tho University and local partners in the provinces. The survey questionnaire was based on sub-components or indicators presented in Table 1.

\section{Results and Discussions}

The drought and SI in 2016 was the worst in Vietnamese Mekong River Delta of the past few years. It caused damages of US $\$ 395$ million to the economy, including 405,000 hectares of rice affected with yields being reduced by $50-100 \%$, or total loss $[11,12]$. However, our surveys in the KG and ST provinces were implemented during 2018, a normal year and not severe saline intrusion, therefore, respondents might not reflect these damages in their answers to some indicators.

LVI values of all 29 sub-components, 9 major components and 5 capitals are presented in Table 2. The overall LVI of KG province is 0.316 which makes KG's livelihoods moderately vulnerable to $\mathrm{CC}$ and SI. This value is relatively higher than the overall LVI of 0.302 of ST province. The following section presents an assessment of vulnerability for all 5 livelihood assets with details.

\subsection{Vulnerability of Human Capital Dimension}

Vulnerability index of Human capital for KG province $(0.355)$ is slightly higher than that of ST (0.331) due to its slightly higher Health, Knowledge and skills, and Livelihood strategy indexes (Table 2). The slightly higher Health index of KG is caused by higher proportion of Hhs with family member illness. 
Table 2 LVI of all sub-component values, major components and capitals for KG and ST provinces.

\begin{tabular}{|c|c|c|c|c|c|}
\hline \multirow{2}{*}{ Capital } & \multirow{2}{*}{ Major component } & \multirow{2}{*}{ Sub-component } & \multirow{2}{*}{ Unit } & \multicolumn{2}{|c|}{ Vulnerability Index } \\
\hline & & & & $\overline{\mathrm{KG}}$ & ST \\
\hline \multirow{14}{*}{ Human } & \multirow{2}{*}{ Health } & (1) Hhs with members illness & $\%$ & 0.370 & 0.330 \\
\hline & & (2) Hhs with members ill due to CC, SI & $\%$ & 0.120 & 0.120 \\
\hline & \multicolumn{2}{|l|}{ Health vulnerability (h1) } & & 0.245 & 0.225 \\
\hline & \multirow{4}{*}{ Knowledge \& skills } & (3) Hhs head unlettered & $\%$ & 0.016 & 0.016 \\
\hline & & (4) Hhs head that just passed primary school & $\%$ & 0.450 & 0.348 \\
\hline & & (5) Hhs head that did do not know CC/SI & $\%$ & 0.130 & 0.100 \\
\hline & & (6) Hhs head with no training to cope with CC/SI & $\%$ & 0.150 & 0.150 \\
\hline & \multicolumn{2}{|c|}{ Knowledge \& skills vulnerability (h2) } & & 0.187 & 0.154 \\
\hline & \multirow{4}{*}{ Livelihood strategy } & (7) Ave. agri. livelihood diversification & 1/\# crops & 0.400 & 0.360 \\
\hline & & $\begin{array}{l}\text { (8) Hhs dependent on agri. as major source of } \\
\text { income }\end{array}$ & $\%$ & 0.950 & 0.950 \\
\hline & & $\begin{array}{l}\text { (9) Hhs with no members doing non-farm } \\
\text { activities }\end{array}$ & $\%$ & 0.900 & 0.900 \\
\hline & & (10) Hhs with no job during SI period & $\%$ & 0.060 & 0.040 \\
\hline & \multicolumn{2}{|c|}{ Livelihood strategy vulnerability (h3) } & & 0.578 & 0.563 \\
\hline & \multicolumn{2}{|c|}{ Human vulnerability $(\mathrm{H})$ : weighted ave. of $\mathrm{h} 1, \mathrm{~h} 2, \mathrm{~h} 3$} & & 0.355 & 0.331 \\
\hline \multirow{10}{*}{ Natural } & \multirow{4}{*}{ Land \& resources } & (11) Hhs who are landless & $\%$ & 0.050 & 0.050 \\
\hline & & (12) Hhs that do not cultivate $2 / 3$ crops & $\%$ & 0.110 & 0.130 \\
\hline & & (13) Hhs that depend on freshwater & $\%$ & 0.070 & 0.070 \\
\hline & & (14) Hhs that have water shortage in dry season & $\%$ & 0.140 & 0.155 \\
\hline & \multicolumn{2}{|c|}{ Land \& resources vulnerability $(\mathrm{n} 1)$} & & 0.093 & 0.101 \\
\hline & \multirow{3}{*}{ Natural disasters \& CC } & $\begin{array}{l}\text { (15) Ave. No. of most severe CC/SI in the past } 10 \\
\text { years }\end{array}$ & No. & 0.205 & 0.195 \\
\hline & & (16) Ave. Hhs with land affected by CC/SI & $\%$ & 0.980 & 0.960 \\
\hline & & $\begin{array}{l}\text { (17) Ave. Hhs with accident due to CC/SI in the } \\
\text { past } 20 \text { years }\end{array}$ & No. & 0.380 & 0.380 \\
\hline & \multicolumn{2}{|c|}{ Natural disasters \& CC vulnerability (n2) } & & 0.522 & 0.512 \\
\hline & \multicolumn{2}{|c|}{ Natural vulnerability $(\mathrm{N})$ : weighted ave. of $\mathrm{n} 1, \mathrm{n} 2$} & & 0.276 & 0.277 \\
\hline \multirow{4}{*}{ Physical } & \multirow{3}{*}{$\begin{array}{l}\text { Housing \& production } \\
\text { means }\end{array}$} & (18) Hhs with temporary house & $\%$ & 0.120 & 0.050 \\
\hline & & (19) Hhs with no access to production means & $\%$ & 0.090 & 0.050 \\
\hline & & $\begin{array}{l}\text { (20) Hhs with no access to salinity prevention } \\
\text { dykes }\end{array}$ & $\%$ & 0.180 & 0.110 \\
\hline & Physical vulnerability & & & 0.130 & 0.070 \\
\hline \multirow{9}{*}{ Social } & \multirow{4}{*}{ Socio-demographic } & (21) Dependency ratio & Ratio & 0.580 & 0.568 \\
\hline & & (22) Female head Hhs & $\%$ & 0.055 & 0.053 \\
\hline & & (23) Ave. members in an $\mathrm{Hh}$ & Person & 0.270 & 0.255 \\
\hline & & (24) No. poor Hhs & $\%$ & 0.070 & 0.040 \\
\hline & \multicolumn{2}{|c|}{ Socio-demographic vulnerability (s1) } & & 0.244 & 0.229 \\
\hline & & (25) Hhs not members of any organizations & $\%$ & 0.770 & 0.755 \\
\hline & Social networks & $\begin{array}{l}\text { (26) Hhs that did not receive help due to disaster } \\
2016\end{array}$ & $\%$ & 0.120 & 0.120 \\
\hline & Social networks vulneral & bility (s2) & & 0.445 & 0.438 \\
\hline & Social vulnerability $(\mathrm{S})$ : & weighted ave. of s1, s2 & & 0.311 & 0.299 \\
\hline & & (27) Hhs that borrowed money & $\%$ & 0.463 & 0.440 \\
\hline Finon & Finance \& income & (28) Hhs with net income lower US $\$ 1,000 /$ year & $\%$ & 0.135 & 0.117 \\
\hline Finance & & (29) Hhs with no income due to SI & $\%$ & 0.569 & 0.537 \\
\hline & Finance \& income vulne & rability $(\mathrm{F})$ & & 0.389 & 0.365 \\
\hline LVI (wei & ed ave. of $H, N, P, S, F)$ & & & 0.316 & 0.302 \\
\hline
\end{tabular}


$\mathrm{KG}$ also has a higher Knowledge and skills index than ST $(0.187$ vs. 0.154$)$. This is caused by higher index of Hh heads that just passed primary school of KG (0.450 vs. 0.348$)$. In terms of Livelihood strategies, KG has slightly higher vulnerability index than ST (0.578 vs. 0.563$)$ due to high numbers of Hhs with being jobless during SI period.

In term of Human capital index, details indicated that the higher index of $\mathrm{KG}$ is mainly from these sub-components: percentage of Hhs with member's illness, percentage of Hhs that do not know CC/SI, diversification of agricultural livelihood and percentage of Hhs with being jobless during SI period. This result shows that interventions such as improvement of health care, providing more information or early warning of CC/SI to community, diversification of income sources, and engaging into more non-farm activities can reduce the vulnerability to $\mathrm{CC}$ and $\mathrm{SI}$ in these regions.

\subsection{Vulnerability of Natural Capital Dimension}

One assessing vulnerability components of Natural Capital, it appears that land and resources index of ST tends to be slightly higher than that of KG. This is due to many farmers that did not cultivate $2 / 3$ crops of rice and needed freshwater for growing vegetable during SI period. However, KG province has higher index on natural disasters and $\mathrm{CC}$ than ST province $(0.522$ vs. 0.512$)$, this due to in $\mathrm{KG}$ rice farming is predominant and most rice land in $K G$ is affected by SI, especially worst drought and SI in 2016.

As a result, natural capital vulnerability index for both KG and ST is not high and the same ( 0.276 vs. $0.277)$. The fact is that both provinces are located in different agro-ecological zone but getting similar impacts of SI. Remarkably, many people in these areas have had good agricultural practices to adapt to $\mathrm{CC} / \mathrm{SI}$ such as making use of saline water as a beneficial resource. This result reveals that local people have a good strategy of land and resources management, remarkably using saline water as beneficial resource in agricultural production.

\subsection{Vulnerability of Social Capital Dimension}

The KG province has dependency ratio and proportion of poor Hhs slightly higher than ST province $(0.580$ vs. 0.568 , and 0.070 vs. 0.040 , respectively), $\mathrm{KG}$ also has members in an Hh slightly higher than ST $(0.270$ vs. 0.255$)$. These three sub-components form a higher socio-demographic component index (0.244 vs. 0.229$)$. $\mathrm{KG}$ also has a higher social networks index $(0.770$ vs. 0.755$)$ because of higher proportion of Hhs that have not been a member of any organizations $(77.0 \%$ vs. $75.5 \%$ ). This reveals that there is a need for strengthening community networks and local organizations such as Woman Union, Farmer Associations, etc. at the community/village level to reduce social capital vulnerability. The weighted average of socio-demographic and social networks components that construct the social vulnerability index of KG is slightly higher than that of ST (0.311 vs. 0.299 ). This slightly higher index does not relate to the agro-ecological zone of KG in West Sea climate, but this can be improved by social programs.

\subsection{Vulnerability of Physical Capital Dimension}

From the survey results it is indicated that KG has a higher proportion of Hhs with temporary houses than ST $(12.0 \%$ vs. $05.0 \%)$. The status of housing situations reflects Hhs economic conditions and their capacity to lessen or cope with environmental changes, natural disaster. Results from survey also showed that the proportions of Hhs with no access to production means and Hhs with no access to salinity prevention dykes for KG are slightly higher than that for ST ( $9 \%$ and $18 \%$ vs. $5 \%$ and $11 \%$, respectively). The combination of these three sub-components provides a lower index in both provinces, however $\mathrm{KG}$ has slightly higher physical vulnerability index than ST (0.130 vs. 0.070$)$. This higher index of KG associates 
with Hhs economy status and the local infrastructure where they live. This result reveals that interventions such as improvement of infrastructure, can reduce the vulnerability to $\mathrm{CC}$ and SI in these areas.

\subsection{Vulnerability of Financial Capital Dimension}

In $\mathrm{KG}$ province, $46.3 \%$ of Hhs have to borrow money during SI period, while that proportion in ST is $44.0 \%$. KG also has a higher proportion of Hhs without income during the SI period and net income below US $\$ 1,000(56.9 \%$ vs. 53.7 and $13.5 \%$ vs. $11.7 \%$, respectively). These three sub-components form a slightly higher financial vulnerability index of KG than that of ST (0.389 vs. 0.365$)$. This result also reveals that interventions such as improvement of financial policy such loan providing, more job for generating income should be taken into account for reducing livelihood vulnerability.

In overall, LVI of KG province is slightly higher than that of ST province ( 0.316 vs. 0.302$)$, indicating $\mathrm{KG}$ has relatively more vulnerability to climate variability and SI as compared to ST. The results of seven major components are presented collectively in a spider diagram (Fig. 2) with scale in 0.1 unit increment, from 0 (less vulnerable) at the center of the web to 0.6 (most vulnerable) at the outside edge. The diagram reflects well that $\mathrm{KG}$ is relatively more vulnerable in most components, in particular natural disaster and CC, social demographic, knowledge and skills, finance and incomes, social networks, and livelihood strategy; whereas ST province is slightly more vulnerable in land and resources component. With the same trend, the diagram in Fig. 3 shows that $\mathrm{KG}$ province is more vulnerable in all capitals compared to ST province, with slightly higher than that of physical, financial, human and social capitals, except natural capital. These results indicate clearly capitals such as financial, human, natural and social capitals, and major components such as livelihood strategy, social networks, finance \& income, etc. should be taken into account for reducing livelihood vulnerability of these two coastal provinces.

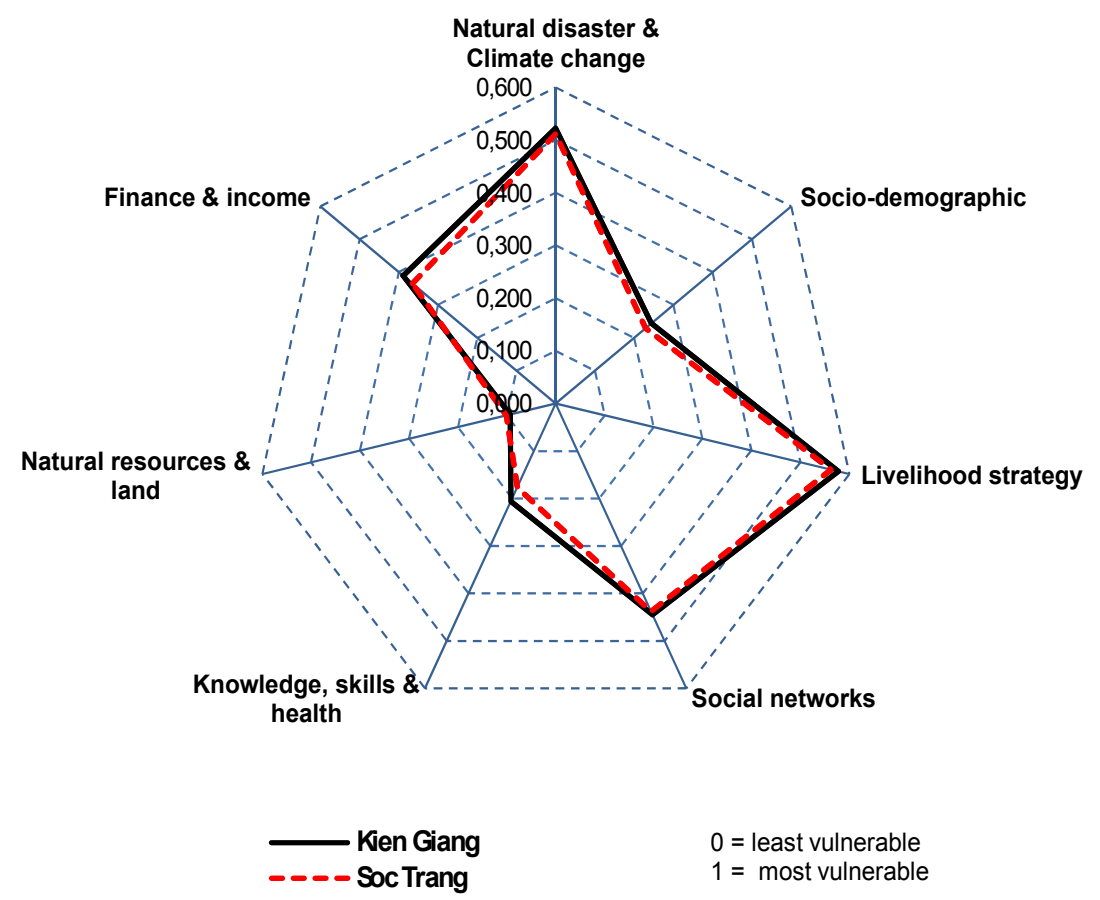

Fig. 2 Vulnerability diagram of major components in KG and ST provinces. 


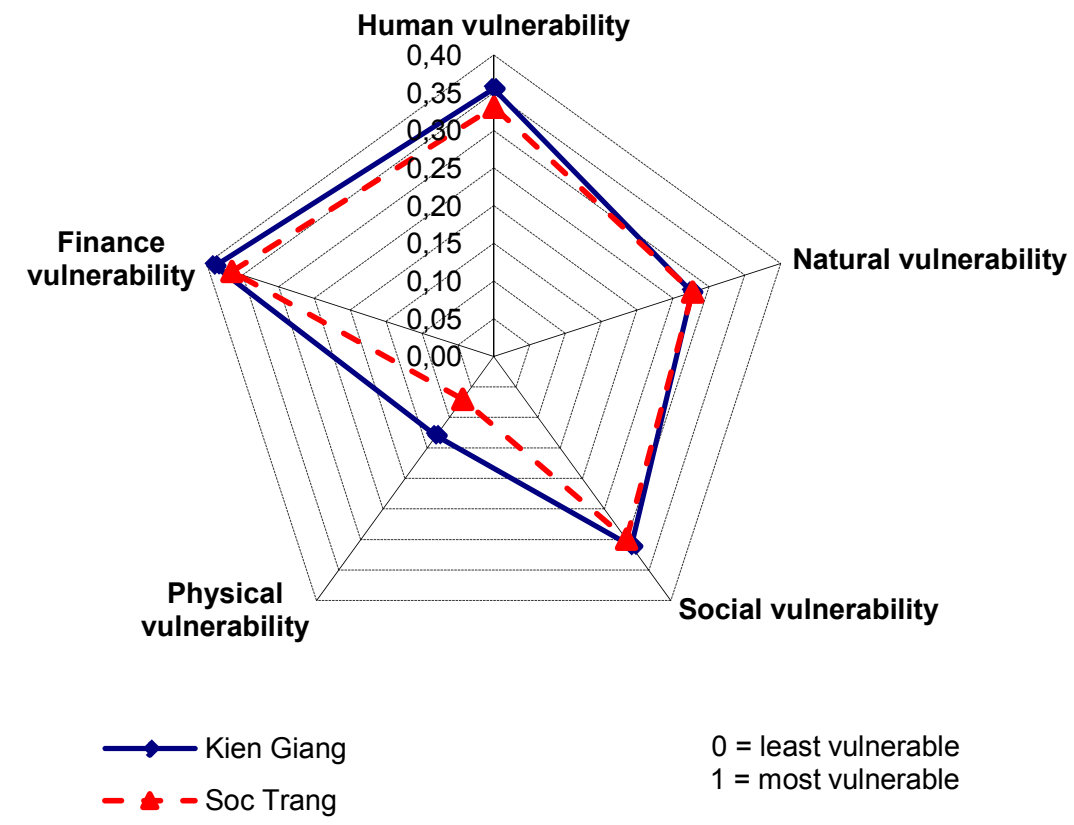

Fig. 3 Vulnerability diagram of five livelihood capitals in KG and ST provinces.

\section{Conclusions}

This case study was conducted in two coastal provinces of the Mekong River Delta to access livelihood vulnerability by focusing on some major components that impacted on Hhs livelihood assets due to impacts of CC/SI. The sub-components used to construct the LVI in this study were based on the current conditions of our study sites, available data from Hh surveys and focus group discussions, which formed 29 indicators distributed to five capitals of livelihood assets.

Results from this research showed that KG province, supposedly affected by West Sea climate, is more vulnerable to $\mathrm{CC} / \mathrm{SI}$ than $\mathrm{ST}$ province-supposedly affected by East Sea climate. The results also revealed that $\mathrm{KG}$ is relatively more vulnerable in most components, in particular natural disaster and $\mathrm{CC}$, social demographic, knowledge and skills, finance and incomes, social networks, and livelihood strategy; whereas ST province is slightly more vulnerable in land and resources component. With the same trend, $\mathrm{KG}$ province is more vulnerable in all capitals compared with ST province, with slightly higher than that of physical, financial, human, and social capitals, except natural capital. These results indicate clearly which capitals and components should be taken into account for reducing livelihood vulnerability of these two coastal provinces.

It was suggested that the LVI analysis could be applied as a practical method to identify vulnerable communities, to understand factors contributing to vulnerability at different levels and also to prioritize the potential interventions recommended to policy makers, local authorities and development organizations.

\section{Acknowledgments}

This paper is an output from projects funded by the Vietnamese Government through Ministry of Education and Training, Can Tho University. The authors would like to express their sincere gratitude to these supporters. The authors also wish to acknowledge the generous support of all researchers and institutions, especially the leaders of $\mathrm{KG}$ and ST provincials DARD (Department of Agricultural and 
Rural Development), the leaders of An Minh and My Xuyen districts, and farmers who closely worked with us during study.

\section{References}

[1] UN in Vietnam. "Vietnam: Sea-Level Rise Could 'Displace Millions'." Accessed November 10, 2018. http://www.un.org.vn/en/un-in-the-news9/160-general/18 12-vietnam-sea-level-rise-could-qdisplace-millionsq.html.

[2] Wassmann, R., Hien, N. X., Hoanh, C. T., and Tuong, T. P. 2004. "Sea Water Rise Affecting the Vietnamese Mekong Delta: Water Elevation in the Flood Season and Implications for Rice Production." Climate Change 66: 89-107.

[3] Birkmann, J. 2006. Measuring Vulnerability to Natural Hazards: Towards Disaster Resilient Societies. Tokyo, New York, Paris: United Nations University Press, pp. 9-54.

[4] DFID. 2000. Sustainable Livelihoods Guidance Sheets, DFID (Department for International Development). London, UK.

[5] Khajuria, A., and Ravindranath, N. H. 2012. "Climate Change Vulnerability Assessment: Approaches DPSIR Framework and Vulnerability Index." J. Earth Sci. Climate Change 3 (1): 109 . doi: 10.4172/2157-7617.1000109.

[6] Hahn, M. B., Riederer, A. M., and Foster, S. O. 2009. "The Livelihood Vulnerability Index: A Pragmatic Approach to Assessing Risks from Climate Variability and Change-A Case Study in Mozambique.” J. Global Environ. Change 19 (1): 74-88.
[7] Can, N. D., Tu, V. H., and Hoanh, C. T. 2013. "Application of Livelihood Vulnerability Index to Access Risks from Flood Vulnerability and Climate Variability-A Case Study in the Mekong Delta of Vietnam." Journal of Environmental Science and Engineering 2 (8): 476-86.

[8] Lamichhane, K. 2010. "Sustainable Livelihood Approach in Assessment of Vulnerability to the Impacts of Climate Change: A Study of Chhekampar VDC, Gorkha District of Nepal, BA.” PhD thesis, National College, Baluwatar, Kathmandu, Nepal.

[9] Shah, K. U., Dulal, H. B., Johnson, C., and Baptiste, A. 2013. "Understanding Livelihood Vulnerability to Climate Change: Applying the Livelihood Vulnerability Index in Trinidad and Tobago." Geoforum 47: 125-37.

[10] Etwire, P. M., Al-Hassan, R. M., Kuwornu, J. K. M., and Osei-Owusu, Y. 2013. "Application of Livelihood Vulnerability Index in Assessing Vulnerability to Climate Change and Variability in Northern Ghana." Journal of Environment and Earth Science 3 (2): 162-70.

[11] CCAFC-SEA. 2016. "CGIAR Research Program on Climate Change, Agriculture and Food Security, Southeast Asia (CCAFC-SEA)." Assessment Report: The drought and salinity intrusion in the Mekong River Delta of Vietnam. Hanoi, Vietnam. Accessed December 10, 2018. https://ccafs.cgiar.org/.

[12] Toan, T. Q., Thang, T. D., and Tuan, T. M. 2017. "Severely Drought and Salinity Intrusion in the Mekong Delta in Year 2016 and Early Warning from the Research on Impact of Upstream Development Analysis." Accessed December 10, 2018. https://www.researchgate.net/publication/. 